\title{
COMUNICAÇÃO
}

\section{INCIDÊNCIA DE Colletotrichum spp. EM FRUTOS DE Coffea arabica L. EM DIFERENTES ESTÁDIOS FISIOLÓGICOS E TECIDOS DO FRUTO MADURO ${ }^{1}$}

\author{
Incidence of Colletotrichum spp. in Coffea arabica L. fruits at different \\ physiological stages and tissues mature of berries
}

\author{
Josimar Batista Ferreira ${ }^{1}$, Mario Sobral de Abreu ${ }^{2}$, Igor Souza Pereira ${ }^{3}$
}

\begin{abstract}
RESUMO
Espécies de Colletotrichum estão presentes em todos os órgãos do cafeeiro. A importância desses fungos para a cultura do cafeeiro ainda é muito discutida, pois tratam-se de populações de espécies de Colletotrichum ocasionando diversos sintomas ou colonizando as plantas de forma endofítica. O estudo foi realizado com o objetivo de verificar a presença de Colletotrichum spp. em diferentes estádios de desenvolvimento do fruto de cafeeiro e nos tecidos do exocarpo+mesocarpo, endocarpo e endosperma de frutos maduros. Este trabalho foi realizado no Laboratório de Diagnose e Controle de Enfermidades de Plantas da Universidade Federal de Lavras-(UFLA). Os frutos foram coletados na área experimental do Setor de Cafeicultura da UFLA com cafeeiros das cultivares Catuaí Vermelho, Catuaí Amarelo, Icatu, Topázio, Katipó, Rubi, Acaiá Cerrado e Mundo Novo. Nos estádios de formação do fruto, verificaram-se altos valores de incidência, com média de $86,6 \%$. Em relação às cultivares, as maiores incidências foram em Topázio e Rubi, ambas com 94,4\% e as menores incidências nas cultivares Icatu e Mundo Novo, com 72,8\% e 78,4\%, respectivamente. A incidência de Colletotrichum spp. variou tanto entre cultivares como entre os tecidos do fruto. No exocarpo+mesocarpo, as cultivares Topázio, Rubi e Acaiá Cerrado tiveram porcentagens de colonizações de 84,72\%, 79,16\% e 77,77\%, respectivamente, enquanto a cultivar Icatu teve 48,6\%. No endocarpo, a máxima colonização foi de 9,72\% na cultivar Rubi e a menor colonização na cultivar Acaiá Cerrado, com 1,39\%. No endosperma, a cultivar Rubi teve novamente o maior índice de colonização (8,33\%) e as cultivares Mundo Novo e Katipó ambas com 1,39\% de colonização. Verificou-se a presença de Colletotrichum spp. nas sementes de todas as cultivares estudadas.
\end{abstract}

Termos para indexação: Colletotrichum gloeosporioides, cafeeiros, colonização, frutos.

\section{ABSTRACT}

Colletotrichum species are present in all organs of coffee trees and the importance of them is still controversial, since several populations can infect plant and cause disease or colonize plants in an endophytic form. This study was carried out with the objective to verify the presence of Colletotrichum spp. in different stages of development of coffee fruits and in the exocarp plus mesocarp, endocarp and endosperm of ripe fruits. In Fruits from the cultivars Catuaí Amarelo and Vermelho, Icatu, Topázio, Katipó, Rubi, Acaiá Cerrado and Mundo Novo came from the experimental farm the of Federal University of Lavras, Brazil. In the developing young fruits Colletotrichum spp. occurred at the average incidence of $86.6 \%$. The highest incidence, $94.4 \%$ was observed in fruits from Topázio and Rubi cultivars, and the lowest incidences were $72.8 \%$ and $78.4 \%$, in fruits from Icatu and Mundo Novo cultivars, respectively. Incidence of Colletotrichum spp. in the tissues of coffee berries varied according to the cultivar and the type of infected tissue. Based on exocarp plus mesocarp infection, the cultivars Topázio, Rubi, Acaiá Cerrado and Icatu were colonized with $84.72 \%$, $79.16 \%, 77.77 \%$ and $48.6 \%$, respectively. In relation to endocarp the maximum colonization was of $9.72 \%$ in cultivar Rubi and lower percentage of colonization was observed in Acaiá Cerrado with 1.39\%. In relation to endosperm, the maximum colonization was observed in Rubi cultivar with $8.33 \%$ and lower percentage of colonization was observed in Mundo Novo and Katipó cultivars, both with $1.39 \%$. Colletotrichum spp. was present in the seeds of all cultivars studied.

Index terms: Colletotrichum gloeosporioides, coffee trees, colonization, berries.

(Recebido para publicação em 13 de maio de 2004 e aprovado em 5 de abril de 2005)

O gênero Colletotrichum é freqüientemente relatado em diferentes espécies de plantas cultivadas em todo o mundo causando doenças e/ou de forma saprófita (LOPEZ, 2001). A ocorrência de danos ocasionados por Colletotrichum spp. na cultura do café (Coffea arabica L.) em Minas Gerais está aumentando com o passar dos anos (OROZCO MIRANDA, 2003), fato importante, especialmente para as grandes regiões produtoras, como o Sul de Minas; portanto há necessidade de se estudar o patossistema Colletotrichum spp. x cafeeiros para melhor entendimento das suas interações.

Estudos de patogenicidade de Colletotrichum spp. têm sido realizados em várias ocasiões. No cafeeiro, os testes de patogenicidade de Colletotrichum spp. são realizados em hipocótilos ou em frutos verdes. Nos ensaios de inoculações de Colletotrichum spp. em frutos verdes

\footnotetext{
${ }_{1}^{1}$ Parte da dissertação apresentada à Universidade Federal de LavraS/UFLA - Pelo primeiro autor, para obtenção do grau de mestre em Agronomia, área de Fitopatologia.

${ }^{2}$ Professor Adjunto do Departamento de Fitopatologia/UFLA - Caixa Postal 3037 - 37200-000 - Lavras, MG

${ }^{3}$ Doutorando em Fitopatologia/UFLA.
} 
de café em fase de desenvolvimento, observaram-se diferentes comportamentos de suscetibilidade (ALMEIDA et al., 1979; DORIZZOTTO, 1993; FIGUEREDO \& MARIOTTO, 1978; NECHET \& ABREU, 2002; OROZCO MIRANDA, 2003; VARGAS \& GONZALEZ, 1972).

No Quênia e em outros países da África, a antracnose das bagas verdes do café, conhecida como "Coffee Berry Disease" (CBD) (Colletotrichum kahawae), é o principal fator limitante à produção dos cafeeiros, podendo levar a uma redução na produtividade entre $50 \%$ e $80 \%$ (CHEN, 2002; GRIFFITHS et al., 1971). O fungo infecta frutos verdes em todos os estádios de desenvolvimento, inclusive as flores e, ocasionalmente, as inflorescências não abertas e folhas (FIRMAN \& WALLER, 1977). Os frutos podem cair prematuramente ou permanecem mumificados na planta (CHEN, 2002).

Segundo Paradela Filho et al. (2001), as lesões mais críticas e prejudiciais para o cafeeiro são aquelas nas quais o fungo (Colletotrichum spp.) incide sobre gemas, flores e chumbinho, provocando sua morte e queda, bem como o enegrecimento e morte dos ramos. Alves \& Castro (1998) mencionam que Colletotrichum spp. podem ser encontrados no fruto do cafeeiro nas fases verde-cana e cereja.

Objetivou-se verificar a presença de Colletotrichum spp. em diferentes estádios de desenvolvimento do fruto do cafeeiro e nos tecidos do exocarpo, mesocarpo, endocarpo e endosperma de frutos maduros.

Foram realizados dois ensaios em condições de laboratório. No primeiro, estudou-se a incidência de Colletotrichum spp. avaliada pela presença do fungo nos diferentes estádios de desenvolvimento do fruto desde a formação inicial até a fase cereja. No segundo, estudou-se a incidência de Colletotrichum spp. avaliada pela presença do fungo no exocarpo, mesocarpo, endocarpo e em endosperma de frutos maduros.

Em ambos os ensaios foram utilizadas oito cultivares: Icatu IAC 3282, Acaiá Cerrado MG-1474, Catuaí Amarelo IAC 62, Catuaí vermelho IAC 15, Rubi-MG 1192, Topázio MG 1190, Mundo Novo IAC 379-19 e Katipó. Os frutos foram obtidos no ensaio de seleção e determinação da estabilidade fenotípica de progênies de Mundo Novo, Catuaí Vermelho, Catuaí Amarelo, Acaiá, Rubi e Topázio na região Sul de Minas Gerais, localizado no campus da UFLA.

O experimento foi conduzido no Laboratório de Diagnose e Controle de Enfermidades de Plantas da UFLA. Avaliou-se a incidência de Colletotrichum spp. sobre frutos em cinco estádios de formação (chumbinho1, fruto verde1, fruto verde 2 , fruto verde 3 e verde-cana) em cada cultivar anteriormente referida, conforme descrito por Rena \& Maestri (1986).

Para cada avaliação, foram colhidos 100 frutos ao acaso, em sete plantas por cultivar. Estes frutos foram levados ao laboratório, onde foram selecionados e padronizados os estádios de formação; em seguida, realizou-se corte transversal para obter duas bandas do fruto num mesmo corte. Estas foram desinfestadas em álcool $(70 \%)$ e hipoclorito de sódio (1\%) por um minuto e meio, lavadas em água destilada e esterilizada e secas em papel de filtro esterilizado. Posteriormente, foram transferidos para placa de Petri com meio de cultura MEA $2 \%$ (extrato de malte-ágar + estreptomicina) e incubadas em câmara de crescimento a $23 \pm 2^{\circ} \mathrm{C}$ e fotoperíodo de 12 horas.

O delineamento foi inteiramente casualizado com cinco repetições. As avaliações da incidência de Colletotrichum spp. foram realizadas por meio da verificação da presença ou não do fungo ao sexto dia após a incubação.

Avaliou-se também a incidência de Colletotrichum spp. sobre os tecidos constituintes do fruto: exocarpo, mesocarpo, endocarpo e endosperma. Para cada avaliação, foram colhidos 50 frutos ao acaso, em sete plantas por cultivar, os quais foram levados ao laboratório, procedendo-se conforme descrito anteriormente.

O delineamento foi inteiramente casualizado com três repetições. As avaliações da incidência de Colletotrichum spp. foram realizadas ao sexto dia após a incubação, por meio da verificação da presença ou não do fungo.

Com os dados de incidência, avaliada pela presença de Colletotrichum spp. nos frutos de cafeeiros, foram realizadas análises de variância com o programa SISVAR 4.0 do Departamento de Estatística da UFLA (FERREIRA, 2000). Para a comparação de médias utilizou-se o teste de Tukey (pd"0,05\%).

A incidência de Colletotrichum spp. avaliada pela presença do fungo em meio MEA $2 \%$, não diferiu entre os estádios de formação do fruto que, na média, atingiu $86,6 \%$ de colonização, com 90,5\% no estádio chumbinho e 82,0\% no estádio verde-cana.

Estes resultados evidenciam a presença de colonização endofítica de Colletotrichum spp. a qual é independente do estádio de formação do fruto, o que pode vir a ser um problema para a cultura do café devido à sua transmissão pelas sementes (OROZCO MIRANDA et al., 
2002a, c), as quais são usadas na formação de novas lavouras.

Almeida et al. (2002), estudando a microbiota endofítica presente em folhas e hastes do cafeeiro, encontraram duas espécies de Colletotrichum, além de outros patógenos, como Cladosporium sp, Fusarium sp. e Phoma sp. Estes autores concluíram que várias dessas espécies são patógenos em potencial. No mesmo segmento, vários autores já observaram colonização sistêmica (endofítica) de fungos associados ao cafeeiro, como Phoma sp., Bipolaris sp., Fusicoccum sp., Cladosporium sp., Aspergillus sp., Penicillium sp., Phomopsis sp., Fusarium sp. e Colletotrichum spp., entre outros (OROZCO MIRANDA et al., 2002a, b, c, d; PARESQUI et al., 2003; ROLDÃO, 2002; SAKIYAMA et al., 2003).

Com relação as cultivares, verificaram-se diferentes porcentagens de incidência de Colletotrichum spp. (Tabela 1). Na análise de variância da incidência da doença, houve apenas diferenças significativas entre as cultivares. As cultivares Rubi e Topázio foram as mais infectadas, ambas com 94,4\% de colonização, enquanto a cultivar Icatu seguida da Mundo Novo obtiveram os menores índices de colonização, com $72,8 \%$ e $78,4 \%$, respectivamente (Tabela 1). Resultado semelhante foi encontrado por Orozco Miranda (2003). Esta informação permite inferir que estas diferenças entre as cultivares sejam devido à herança genética. A maior resistência da cultivar Icatu ao fungo pode ser bom indício de fonte de resistência para um futuro trabalho de melhoramento visando resistência a Colletotrichum spp.

Carvalho et al. (1976), estudaram linhagens e progênies da cultivar Icatu como fonte de resistência ao CBD (Colletotrichum kahawae), testadas na Coffee Research Station, Ruiru, Quênia. O germoplasma Icatu cruzado com o híbrido de Timor oferece perspectivas de construir razoável fonte de resistência genética a este patógeno.

Ferreira et al. (2003), em estudos preliminares sobre a incidência de Colletotrichum spp. no fruto do cafeeiro, observaram o mesmo comportamento.

Resultados encontrados por Orozco Miranda et al. (2002b, c), estudando a incidência e transmissão de Colletotrichum spp. em sementes de diferentes cultivares de Coffea arabica L., detectaram após a abertura dos primeiros folíolos a presença de Colletotrichum gloeosporioides com as mesmas características morfológicas de colônias originais do fungo, caracterizando a transmissibilidade via semente.

\section{Colletotrichum spp. nos tecidos dos frutos}

Observaram-se diferentes porcentagens de colonização de Colletotrichum spp. nos tecidos do fruto. No exocarpo e mesocarpo, observaram-se diferentes comportamentos entre as cultivares (Tabela 2).

TABELA 1 - Valores médios em porcentagem da incidência de Colletotrichum spp. em frutos de oito cultivares de café arábica.

\begin{tabular}{lc}
\hline \multicolumn{1}{c}{ Cultivares } & Incidência de Colletotrichum $(\%)$ \\
\hline Icatu & $72,8 \mathrm{a}$ \\
Mundo Novo & $78,4 \mathrm{a} \mathrm{b}$ \\
Catuaí Amarelo & $84,0 \mathrm{a} \mathrm{b} \mathrm{c}$ \\
Acaiá Cerrado & $89,6 \mathrm{~b} \mathrm{c}$ \\
Katipó & $89,6 \mathrm{~b} \mathrm{c}$ \\
Catuaí Vermelho & $89,6 \mathrm{~b} \mathrm{c}$ \\
Rubi & $94,4 \mathrm{c}$ \\
Topázio & $94,4 \mathrm{c}$ \\
\hline Médias seguidas de mesma letra não diferem entre si, pelo teste Tukey $(\mathrm{p} \leq 0,05), \mathrm{CV}=16,17 \%$.
\end{tabular}

Ciênc. agrotec., Lavras, v. 29, n. 4, p. 880-885, jul./ago., 2005 
TABELA 2 - Valores médios, em porcentagem da colonização de Colletotrichum spp. nos tecidos do fruto em oito cultivares de café.

\begin{tabular}{lccc}
\hline & \multicolumn{3}{c}{ Colonização de Colletotrichum spp. (\%) } \\
\cline { 2 - 4 } \multicolumn{1}{c}{ Cultivares } & Exocarpo e mesocarpo & Endocarpo* $^{*}$ & Endosperma* $^{*}$ \\
\hline Icatu & $48,60 \mathrm{a}$ & 2,77 & 2,77 \\
Mundo Novo & $65,27 \mathrm{ab}$ & 2,77 & 1,39 \\
Katipó & $73,60 \mathrm{ab}$ & 2,77 & 1,39 \\
Catuaí Vermelho & $70,83 \mathrm{ab}$ & 5,55 & 2,77 \\
Catuaí Amarelo & $75,00 \mathrm{ab}$ & 4,16 & 4,16 \\
Acaiá Cerrado & $77,77 \mathrm{~b}$ & 1,39 & 2,77 \\
Rubi & $79,16 \mathrm{~b}$ & 9,72 & 8,33 \\
Topázio & $84,72 \mathrm{~b}$ & 8,33 & 4,16 \\
\hline
\end{tabular}

* Variáveis não-significativas

Médias seguidas de mesma letra, na coluna, não diferem entre si pelo teste Tukey $(\mathrm{p} \leq 0,05) \mathrm{CV}=13,07 \%$.

Verificou-se maior colonização nas cultivares Topázio, Rubi e Acaiá Cerrado, com 84,72\%, 79,16\% e $77,77 \%$, respectivamente. A menor colonização foi de 48,60\% observada na cultivar Icatu. Nas cultivares Catuaí Vermelho, Catuaí Amarelo, Katipó e Mundo Novo houve colonização de 70,83\%, 75,00\%,73,60\% e 65,27\%, respectivamente (Tabela 2).

No endocarpo, observaram-se diferentes porcentagens de colonização. A maior colonização foi na cultivar Rubi, com 9,72\%, enquanto que cultivar Acaiá Cerrado teve menor índice, com 1,39\% (Tabela 2). No comportamento de suscetibilidade entre as cultivares, destacam-se Acaiá, Mundo Novo, Icatu e Katipó, como as mais resistentes e Rubi e Topázio, como as mais suscetíveis. Em relação ao parentesco destas cultivares, Acaiá Cerrado surgiu a partir da seleção de Mundo Novo, Rubi e Topázio da seleção de Catuaí. Resultados semelhantes foram encontrados por Orozco Miranda et al. (2002a, b). Orozco Miranda (2003) observou diferentes comportamentos entre cultivares e os tecidos do fruto do cafeeiro. No endocarpo, o fungo variou de $0 \%$ - $8 \%$ e na semente, de $0 \%$ - $17 \%$.

No endosperma, observaram-se diferentes comportamentos de colonização de Colletotrichum spp. Os maiores valores foram observadas nas cultivares Rubi, Topázio e Catuaí Amarelo, com 8,33\%, 4,16\% e 4,16\%, respectivamente, enquanto as cultivares Mundo Novo e
Katipó obtiveram os menores percentuais de colonização, ambas com 1,39\% (Tabela 2).

Orozco Miranda et al. (2002a) verificaram incidência de Colletotrichum spp. na semente para as cultivares Catuaí Amarelo e Catuaí Vermelho com sintomas de mancha manteigosa, Catuaí Vermelho e Acaiá Cerrado sem sintomas de mancha manteigosa. Os valores foram 14\%, 10\%, 6\% e $4 \%$, respectivamente. Os autores concluíram que Colletotrichum spp. pode ser transmitido pela semente e aquelas cultivares com sintomas de mancha manteigosa têm maior expressão na transmissibilidade deste patógeno.

As cultivares Topázio e Rubi foram as que apresentaram as maiores porcentagens da presença de Colletotrichum spp. em todos os tecidos estudados, enquanto a Mundo Novo e Icatu tiveram as menores colonizações, sobressaindo-se a cultivar Icatu. Verificouse a presença de Colletotrichum spp. nas sementes de todas as cultivares estudadas.

\section{REFERÊNCIAS BIBLIOGRÁFICAS}

ALMEIDA,A. R.; SALGADO, M.; PFENNING L. H.; LIMA, C. S.; CHAVES, Z. M. Fungos endofíticos de folhas e haste de café (Coffea arabica). In: CONGRESSO BRASILEIRO DE PESQUISAS CAFEEIRAS, 28., 2002, Caxambu-MG. Anais... Caxambu: [s.n.], 2002. p. 432. 
ALMEIDA, S. R.; MANSK, Z.; MATIELLO, J. B.; MULLER, R. A. Observações preliminares sobre queda de frutos sob suspeita de ataque por Colletotrichum sp. In: CONGRESSOBRASILEIRODEPESQUISASCAFEEIRAS, 7., 1979, Araxá-MG. Resumos... Araxá: IBC/GERCA, 1979. p. 323-326.

ALVES, E.; CASTRO, H. A. Fungos associados ao café (Coffea arabica L.) nas fases de pré e pós-colheita em lavouras da região de Lavras. Summa Phytopathologica, Piracicaba, v. 24, n. 1, p. 4-7, jan./mar. 1998.

CARVALHO, A.; MÔNACO, L. C.; VOSSEN, H. A. M. van der. Café Icatu como fonte de resistência a Colletotrichum coffeanum. Bragantia, Campinas, v. 35, n. 28, p. 343-347, out. 1976.

CHEN, Z. Morphocultural and pathogenic comparisons between Colletotrichum kahawae and Colletotrichum gloeosporioides isolated from coffee berries. 2002. $163 \mathrm{f}$. Tese (Doutorado em Engenharia Agronômica) - Instituto Superior de Agronomia da Universidade Técnica de Lisboa, Lisboa, 2002.

DORIZZOTTO, A. Caracterização morfológica e patogenicidade de Colletotrichum sp associados a cafeeiros (Coffea arabica L.) em dois municípios de Minas Gerais. 1993. 67 f. Dissertação (Mestrado em Fitopatologia) - Universidade Federal de Lavras, Lavras, 1993.

FERREIRA, D. F. Análise estatística por meio do SISVAR para Windows: versão 4.0. In: REUNIÃO ANUAL DA REGIÃO BRASILEIRA DA SOCIEDADE INTERNACIONAL DE BIOMETRIA, 45., 2000, São Carlos, SP. Programas e Resumos... São Carlos: UFScar, 2000. p. 235.

FERREIRA, J. B.; MARQUES, D. C.; PEREIRA, I. S.; ABREU, M. S. Estudo da incidência de colletotrichum spp. nos estágios de formação do fruto de diferentes cultivares de Coffea Arabica L. In: CONGRESSO DE PÓS GRADUAÇÃO, 12., 2003, Lavras, MG. Resumos... Lavras: UFLA/APG, 2003.

FIGUEREDO, P.; MARIOTTO, P. R. Colletotrichum gloeosporioides Penz atacando frutos verdes de cafeeiro (Coffea arabica L.). O Biológico, São Paulo, v. 54, n. 1 p. 25-26, jan. 1978.
FIRMAN, I. D.; WALLER, J. M. Coffee berry disease and other Colletotrichum disease of coffee. Phytopathological Papers, CMI, Kew, n. 20, p. 1-53, 1977.

GRIFFITHS, E.; GIBBS, J. N.; WALLER, J. M. Control of coffee berry disease. Annal Applied Biology, London, v. 67, n. 1, p. 45-74, Jan. 1971.

LOPEZ, A. M. Q. Taxonomia, patogênese e controle de espécies do gênero Colletotrichum. Revisão Anual de Patologia de Plantas - RAPP, [S.1.], v. 9, p. 291-338, 2001.

NECHET, K. de L.;ABREU, M. S. Caracterização morfológica e testes de patogenicidade de isolados de Colletotrichum sp. obtidos de cafeeiro. Ciência e Agrotecnologia, Lavras, v. 26, n. 6, p. 1135-1142, nov./dez. 2002.

OROZCO MIRANDA, E. F. Caracterização morfológica, molecular, bioquímica e patogênica de isolados de Colletotrichum spp. associados ao cafeeiro em Minas Gerais e Comparação com Colletotrichum kahawae. 2003. 147 p. Tese (Doutorado em Fitopatologia) - Universidade Federal de Lavras, Lavras, 2003.

OROZCO MIRANDA, E. F.; FREITAS, M.; PIGOZZO, P.; ABREU, M. S. Incidência de Colletotrichum spp. em frutos cereja e sementes de café arabica (Coffea arabica). In: SIMPÓSIOBRASILEIRODEPATOLOGIADESEMENTES, 7., 2002, Sete Lagoas-MG. Anais...SeteLagoas:[s.n.],2002a.p.59.

OROZCO MIRANDA, E. F.; FREITAS, M.; PIGOZZO, P.; ABREU, M. S. Incidência de Colletotrichum spp. em frutos cereja e sementes de café arabica (Coffea arabica) no estado de Minas Gerais. In: CONGRESSO DE PÓS GRADUAÇÃO, 11., 2002, Lavras, MG. Resumos... Lavras: UFLA/APG, 2002b.

OROZCO MIRANDA, E. F.; FREITAS, M.; PIGOZZO, P.; ABREU, M. S. Transmissão de Colletotrichum spp. por sementes de café arabica (Coffea arabica). In: SIMPÓSIO BRASILEIRO DE PATOLOGIA DE SEMENTES, 7., 2002, Sete Lagoas-MG. Anais... Sete Lagoas: [s.n.], 2002c. p. 93.

OROZCO MIRANDA, E. F.; PIGOZZO, P.; PEREIRA, I. S.; ABREU, M. S. Estudo das relações compatíveis e incompatíveis de Colletotrichum spp. x cafeeiro. In: CONGRESSO DE PÓS-GRADUAÇÃO, 11., 2002, Lavras, MG. Resumos... Lavras: UFLA/APG, 2002d. 
PARADELA FILHO, O.; PARADELA, A. L.; THOMAZIELLO, R. A.; RIBEIRO, I. J. A.; SUGIMORI, M. H.; FAZUOLI, L. C. O complexo Colletotrichum do cafeeiro. Campinas: IAC, 2001.11 p. (Boletim técnico, 191).

PARESQUI, L.; ZAMBOLIM, L.; COSTA, H.; SAKIYAMA, C. H.; BATISTA, U. G. Evidências da latência e associação endofítica de Colletotrichum sp. em tecidos de Coffea arabica L. In: SIMPÓSIO DE PESQUISAS DOS CAFÉS DO BRASIL, 3., 2003, Porto Seguro. Anais... Porto Seguro: [s.n.], 2003. p. 200.

RENA, A. B.; MAESTRI, M. Fisiologia do cafeeiro. In: SIMPÓSIO SOBRE FATORES QUE AFETAM A PRODUTIVIDADE DOCAFEEIRO, 1986, Poços de Caldas. Anais... Piracicaba: PATOFOS, 1986. p. 13-85.
ROLDÃO, G. M. Fungos endofíticos em grãos verdes de café (Coffea arabica L.). 2002. 53 p. Dissertação (Mestrado em Fitopatologia) - Universidade Federal de Lavras, Lavras, 2002.

SAKIYAMA, C. H.; PAULA, E. M.; PEREIRA, P. C.; PITTAFILHO, O. P. L.; HARA, A.; BORGES, A. C.; SILVA, D. O. Microbiota endofítica em frutos de Coffea arabica L. In: SIMPÓSIO DE PESQUISAS DOS CAFÉS DO BRASIL, 3., 2003, Porto Seguro. Anais... Porto Seguro: [s.n.], 2003.p. 206.

VARGAS, G.E.; GONZALEZ, U.L.C. La mancha mantecosa del café causada por Colletotrichum spp. Turrialba, San José, v. 22, n. 2, p. 129-135, abr./jun. 1972. 